\title{
Huellas evolucionistas en la literatura proto-antropológica uruguaya sobre los Charrúas en el cambio de siglo (1890-1911)
}

Federico del Castillo*

Fecha de recepción: 10 de abril de 2020. Fecha de aceptación: 30 de junio de 2020

\begin{abstract}
Resumen
Hacia fines del siglo XIX, las corrientes evolucionistas en antropología discutían la distancia que separaba los pueblos primitivos de la civilización occidental. El evolucionismo unilineal de autores como Edward Burnett Tylor o Lewis Henry Morgan planteaba la controversial observación de que los pueblos primitivos eran portadores de cultura, disputando la separación tajante entre las categorías de lo salvaje y lo civilizado sobre la cual se habían erigido las influyentes ideas de Herbert Spencer. Estas discusiones permearon las antropologías y proto-antropologías del mundo, incluyendo la región del Plata. Este artículo examina la influencia de estos debates en Uruguay, a partir del análisis de tres influyentes textos sobre la etnia charrúa escritos en el tránsito del siglo XIX al XX: Los primitivos habitantes del Uruguay (1892), de José Henriques Figueira; Historia de la dominación española en el Uruguay, (1895) de Francisco Bauzá; y Historia de los charrúas y demás tribus indígenas del Uruguay (1911) de Orestes Araújo.
\end{abstract}

\section{Footprints of evolutionism in Uruguay's proto-anthropological} literature about Charruas in the turn of the century (1890-1911)
Palabras clave

evolucionismo charrúas etnohistoria del Uruguay

\begin{abstract}
Toward the end of the $19^{\text {th }}$ century, evolutionist currents in anthropology were discussing the distance between "primitive" people from Western civilization. Unilineal evolutionism attributed to authors such as Edward Burnett Tylor or Lewis Henry Morgan asserted the controversial observation that "primitive" peoples possessed culture, disputing the separation between "savage" and "civilized" categories upon which Herbert Spencer's influential ideas were built. These discussions permeated the world's anthropologies and protoanthropologies, including those in La Plata region. This article examines the
\end{abstract}

Key words

evolutionism Charrúas ethnohistory of Uruguay

* Instituto de Altos Estudios Sociales, Universidad Nacional de San Martín (UNSAM). Ciudad Autónoma de Buenos Aires, Argentina. E-mail: fcodelcastillo@gmail.com 
1. En 1831, el ex presidente de la república, Fructuoso Rivera, organizó una operación de exterminio contra los charrúas, a quienes su sobrino Bernabé Rivera engañó reuniéndolos con el pretexto de que necesitaba su apoyo para defender la frontera. Este episodio se conoce como la matanza de Salsipuedes y se considera el punto cúlmine del exterminio de los charrúas. influence of these debates in Uruguay by analyzing three influential texts about the Charrúa people during the transition from the $19^{\text {th }}$ to the $20^{\text {th }}$ century: José Henriques Figueira's Los primitivos habitantes del Uruguay (1892), Francisco Bauzá's Historia de la dominación española en el Uruguay, (1895) and Orestes Araújo's Historia de los charrúas y demás tribus indígenas del Uruguay (1911).

\section{Introducción}

De los pueblos amerindios que habitaron el actual territorio uruguayo al momento de la conquista, los charrúas son el que ha tenido el mayor peso simbólico en la construcción del ethos nacional uruguayo. Las referencias a esta etnia sobresalen en las crónicas etnohistóricas de colonizadores europeos desde el siglo XVI, en relación con otras poblaciones del área. Esta sobrerrepresentación prefigura la dimensión que lo charrúa adquirió en la producción literaria, histórica y en las bellas artes en siglos posteriores, así como su significado en la construcción del relato nacional uruguayo oficial.

La idea de un Uruguay "sin indios", con ascendencia europea y valores occidentales ha predominado durante la mayor parte de la historia nacional. La reivindicación de una etnicidad charrúa sucedió hace relativamente pocas décadas, a través de la aparición de colectivos que comenzaron a reclamar esa identidad para sí (Verdesio, 2014). Hasta entonces, la representación del indio charrúa en el imaginario colectivo fue vaga y contradictoria, oscilando desde las nociones de bárbaro, salvaje y primitivo hasta la apropiación de un presunto espíritu guerrero y combativo, materializado en la forma de la "garra charrúa" (Cabrera Pérez y Barreto, 1997). Esta última, ha estado principalmente asociada a hazañas futbolísticas como la victoria de Uruguay en la final de la Copa del Mundo de 1950 contra Brasil en el estadio Maracaná.

Azpiroz (2017) distingue dos grandes momentos de representación de lo charrúa en el siglo XIX. El primero, ubicado en los dos primeros tercios del siglo XIX, cuando la formación discursiva en torno a los charrúas fue condicionada por el intento de la elite criolla uruguaya de consolidar el Estado Oriental, construido en oposición a esta etnia. El indio charrúa suponía una amenaza contra los intereses de la elite criolla dominante al punto de que, en palabras de J. H. Figueira, "fue menester destruirlos"1 (Figueira, 1892: 33). El segundo, hacia las últimas décadas de aquel siglo, implicó la configuración de un relato idealizado de un pasado indígena asociado a la construcción de la identidad nacional, que representó a los charrúas como un pueblo incivilizado aunque dotado de una "bondad natural" y "valentía heroica" (Bauzá, [1895] 1965). Este relato se materializó en la obra plástica del pintor Juan Manuel Blanes, la poesía de Juan Zorrilla de San Martín y el trabajo del historiador Francisco Bauzá, por citar algunos ejemplos.

¿Sobre qué bases se forjó la construcción discursiva sobre lo charrúa en la narrativa nacionalista uruguaya?, ¿qué corrientes teóricas influyeron a la intelectualidad criolla a la hora de representar a los charrúas?, ¿cómo se articularon estas influencias teóricas con la representación hegemónica sobre los charrúas vigente en el Uruguay del siglo XIX?

Me interesa aproximarme a estas preguntas apoyándome en algunos textos sobre esta etnia, cuya producción se sitúa en el segundo momento definido por Azpiroz (2017). Específicamente, la ventana de tiempo que ocupa a este examen comprende el fin del siglo XIX y comienzos del XX, una etapa decisiva 
en la modernización del estado nacional. Así, analizaré tres influyentes textos tempranos en la producción discursiva sobre los charrúas haciéndolos dialogar entre sí, con el contexto histórico en que fueron escritos y con las corrientes de pensamiento dominantes en la antropología de la época. Estos textos son: a) Los primitivos habitantes del Uruguay (1892), de José Henriques Figueira; b) Historia de la dominación española en el Uruguay (1895), de Francisco Bauzá; y c) Historia de los charrúas y demás tribus indígenas del Uruguay (1911), de Orestes Araújo. Apoyaré estos movimientos con someras referencias a la iconografía de la época sobre "lo charrúa".

Importa subrayar el carácter proto-antropológico de estos textos. Es decir, textos producidos por autores que no eran antropólogos de profesión, en un contexto donde aún no existía un campo antropológico per se pero que abordan tópicos específicamente antropológicos y revisten influencias teóricas de esta disciplina. La antropología en Uruguay se desarrolla ya avanzado el siglo $X X$, con los trabajos pioneros de Daniel Vidart o Renzo Pi Hugarte -por citar algunos autores-, y la enseñanza profesional de antropología se consolida en 1976. Los textos aquí analizados fueron escritos por pedagogos e historiadores casi cien años atrás, quienes -si bien adoptan un enfoque que podría calificarse de "etnológico" en su contexto de producción- no necesariamente parten de la antropología. Por ejemplo, con la excepción de Spencer en Figueira no hay referencias explícitas en estos materiales a antropólogos influyentes en la época.

Sin embargo, algunas discusiones que atraviesan el campo antropológico de fines del XIX están presentes en los textos en cuestión. El ejercicio que me propongo realizar en estas páginas consiste, justamente, en identificar las huellas de las discusiones del campo antropológico en la narrativa sobre los charrúas en el Uruguay de cambio de siglo (XIX-XX).

\section{Huellas de Spencer en J. H. Figueira}

En la segunda mitad del siglo XIX, Uruguay atravesó importantes cambios hacia la modernización y consolidación del estado-nación. Este período, denominado Militarismo, implicó el ascenso de cuadros castrenses a la conducción estatal: concretamente, las presidencias de Lorenzo Latorre (1876-1880), Francisco Vidal Silva (1876-1880) y Máximo Santos (1882-1886). En estos años, Uruguay centralizó y desarrolló la fuerza y presencia del Estado, concretadas en múltiples reformas orientadas a su modernización. El alambramiento de la tierra, las marcas y señales sobre el ganado, y la creación de la policía rural para reprimir la vagancia y el abigeato contribuyeron a instalar la propiedad privada en el campo. Al mismo tiempo, el tendido de líneas de ferrocarril, la construcción de caminos, puentes y la universalización de la educación primaria, laica y obligatoria, sentaron las bases para transformar el país primitivo del estanciero y el caudillo, en un país moderno de estancieros y empresarios (Barrán, 1968).

Por ese entonces, las ideas de Herbert Spencer ejercían una fuerte influencia en la región del Plata. Domingo Faustino Sarmiento fue uno de sus cultores más resonados en Argentina. Por su parte, José Henriques Figueira siguió su tradición del lado uruguayo. Figueira fue un miembro de la elite criolla nacional, recordado por su labor pedagógica -son conocidos sus libros de escuela: ¿Quieres leer?, Un buen amigo y Trabajo, Vida y Progreso- y por ser considerado el fundador de la arqueología nacional (Pi Hugarte, 1997). En 1890 recibió una beca gubernamental para viajar a Europa, donde cursó estudios 
2. Figueira cita en Los primitivos... a los cronistas Félix de Azara, al Padre Lozano, Ulrico Schmidel, Diego García, Ruy Díaz de Guzmán, Martín del Barco Centenera y Alcide D’Orbigny.

\footnotetext{
3. Entre las razas inferiores, como los san, no encontramos otra cosa sino agregaciones incipientes: algunas veces familias solitarias, o en otras dos o tres familias deambulando juntas. $\mathrm{El}$ número de unidades asociadas es pequeño y variable, y su unión es inconstante. No existe división del trabajo entre los sexos; y el único tipo de ayuda mutua es el ataque o la defensa colectiva. No tenemos aquí otra cosa más que un grupo indiferenciado de individuos formando el germen de una sociedad; igual que en grupos de células similares [...], solo tenemos la etapa inicial de la organización animal y vegetal (Traducción del autor).
}

de antropología en París y Berlín (Scarone, 1937). Allí conoció personalmente a Herbert Spencer, cuya influencia fue determinante sobre su obra. En 1892, el gobierno le encomendó organizar la sección antropológica del Uruguay para la Exposición Histórico Americana de Madrid, y en este contexto escribió Los primitivos habitantes del Uruguay (Figueira, 1892), un texto seminal para la arqueología nacional que puede ser leído como un producto de su época.

En este texto -definido por Figueira como "ensayo paleoetnológico"-, el autor presenta un cuadro general de las características de algunos pueblos indígenas del Uruguay. Desfilan por sus páginas descripciones de los charrúas, bohanés, yaros, chanás, arachanes, guenoas y minuanes basadas en fuentes etnohistóricas, $^{2}$ a falta de datos obtenidos a partir de investigaciones arqueológicas. El autor dedica la mayor parte de su ensayo a los charrúas y realiza descripciones someras del resto de los pueblos. El texto es hijo del paradigma evolucionista que dominaba el campo antropológico por esos años. En particular, son claras las influencias del pensamiento de Spencer. En efecto, el propio autor reconoce que:

El cuadro que pongo al frente da, en resumen, los caracteres individuo-sociales de [los pueblos indígenas descriptos] [...] clasificados según el esquema de Mr. Herbert Spencer, que permite relacionar fácilmente los diversos elementos que caracterizan dichas agrupaciones primitivas (Figueira, 1892: 42).

Una de las principales ideas de la filosofía spenceriana que encontramos en Los primitivos... es la "analogía orgánica", que propone el estudio de las sociedades humanas como organismos biológicos. En The Social Organism (1860), Spencer identifica tres aspectos en los que las sociedades se asemejan a organismos biológicos: 1) ambos parten de pequeños grupos a grandes agregados; 2) de estructuras simples a estructuras complejas y; 3) de un conjunto de unidades independientes a un organismo compuesto de partes interdependientes. Este supuesto encierra la creencia de que la evolución social es progresiva: las sociedades grandes, complejas e integradas están más evolucionadas que las sociedades pequeñas, simples y con bajos niveles de integración. Entonces, si las sociedades se comportan de forma similar a los organismos biológicos, ello significaba que la evolución social podía estudiarse de la misma forma que la evolución biológica. Así, y en diálogo con la teoría de Darwin -aunque principalmente influenciado por ideas lamarckianas-, Spencer planteó que la evolución social ocurría por la competencia entre individuos, en la que aquellos más aptos para la supervivencia prevalecían sobre los demás. Si bien este proceso podría significar miseria para algunos, en última instancia significaba el progreso general para la sociedad. El resultado de la evolución era la eliminación de los problemas sociales y el perfeccionamiento de la sociedad.

Un pasaje de la obra The Social Organism ilustra las similitudes entre sociedades simples y organismos simples:

Among the lowest races, as the Bushmen, we find but incipient aggregations: sometimes single families, sometimes two or three families wandering about together. The number of associated units is small and variable, and their union inconstant. No division of labor exists except between the sexes; and the only kind of mutual aid is that of joint attack or defence. We have nothing beyond an undifferentiated group of individuals forming the germ of a society; just as in the groups of similar cells [...], we have only the initial stage of animal and vegetal organization (Spencer, 1860: 100). ${ }^{3}$ 
Es notable en este párrafo la descripción a través de la ausencia de cualidades. No aparece aquí asociación entre unidades -familias- ni cohesión entre ellas, así como tampoco división del trabajo, asistencia mutua ni diferenciación entre individuos. Lo mismo ocurre en la descripción que realiza Figueira sobre los pueblos primitivos de Uruguay, principalmente de los charrúas. Para este autor, los charrúas no tenían leyes ni religión y tampoco existía entre ellos división del trabajo ni diferenciación social entre individuos al interior de la tribu. Los charrúas no tenían "consideración de respeto y urbanidad", ni bailes, ni canciones, ni instrumentos musicales, ni conversaciones ociosas, y carecían de adornos y "sentimientos estéticos" (Figueira, 1892). Vivían en un "estado social rudimentario" y sus ideas eran "limitadísimas". Del mismo modo en que Spencer describe a los san, Figueira describe a los charrúas como una sociedad pequeña, simple y con bajo nivel de integración entre sus unidades. Es decir, una sociedad inferior a la civilización criolla -Spencer diría a la civilización inglesa industrial-, incapaz de adaptarse a la vida civilizada y que, por ende, "fue menester destruirlos" ${ }^{4}$ (Figueira, 1892: 33).

No sólo encontramos la influencia de Spencer en la descripción de Figueira sobre la organización social charrúa, sino también en la descripción de su mentalidad. En The principles of Sociology (1876-96), Spencer representa el carácter moral e intelectual de las "razas inferiores". ${ }^{5}$ La impulsividad y la imprevisión, entendida como el deseo inmediato de la gratificación sin medir consecuencias, constituyen -para este autor- rasgos definitorios de estas razas. Incapaces de concebir el futuro, los salvajes se encuentran absorbidos por el presente y la inmediatez. Tampoco toleran ningún tipo de límites a su conducta, son vengativos y, en general, brutales e insensibles hacia las mujeres. En cuanto a sus características intelectuales, los salvajes tienen una percepción aguda de la naturaleza y son hábiles en las acciones que requieren alta percepción. Sin embargo, carecen de curiosidad e imaginación constructiva, son incapaces de producir pensamientos deliberados, ni tienen idea alguna de cualquier tipo de relación causal. Estas cualidades suelen volverlos víctimas de su credulidad e incapacidad para producir un pensamiento racional. Quizá la siguiente frase de Spencer sirva para sintetizar las cualidades emocionales del salvaje: "the savage has the mind of a child with the passions of a man (or, rather, has adult passions which act in a childish manner )"6 (Spencer: 59-60, en Stocking, 1991).

Por su parte, en Los primitivos..., Figueira describe a los charrúas como vengativos, poco perseverantes -salvo en el espionaje y la caza- y "de escasa inventiva", cualidades que evocan la descripción de Spencer sobre los pueblos salvajes. Esta falta de cualidades y de inteligencia volvían a los charrúas, según Figueira, "víctimas de su credulidad". No es descabellado arriesgar la hipótesis de que tal vez, al escribir estas líneas, nuestro autor tuviera en mente el engaño de Rivera a los charrúas en la matanza de Salsipuedes.

Figueira, por supuesto, no fue el primero en representar a los charrúas de esta forma. Las pocas piezas iconográficas sobre esta etnia de la primera mitad del siglo XIX que han sobrevivido al paso del tiempo, también los representa acentuando su carácter salvaje y belicoso.

Ejemplo de ello es la famosa litografía "Indiens Charruas" de Arthur Onslow (1833), que representa a Laureano Tacuabé, Vaimaca Perú, María Guyunusa y Senacua Senaqué, los cuatro charrúas que François de Curel llevó a Francia para exhibirlos en su zoológico humano. El folleto utilizado por Curel para promocionar a los indígenas incluía la litografía de Onslow, acompañada de
4. Verdesio (2005) advierte el carácter significativo de esta afirmación, casi autocomplaciente, que justifica la destrucción de los charrúas por parte del estado como un acontecimiento inevitable, pues es esta la primera vez que encontramos un autor de esta época que "Ilama las cosas casi por su nombre" y reconoce que los charrúas no desaparecieron sino que fueron exterminados intencionalmente.

5. Tomado de Stocking (1991).

6. El salvaje tiene la mentalidad de un niño con las pasiones de un hombre (o, más bien, tiene pasiones adultas, pero actúa como un niño). (Traducción del autor). 
la siguiente descripción que resaltaba las cualidades guerreras y mágicas -exóticas- de los charrúas:

El primero es un cacique temible [Perú]; el segundo [Senaqué], uno de los por ellos denominado médico, que tiene la pretendida ciencia de la magia médica, añadiendo realmente el conocimiento de simples adecuados para curar las heridas. El tercero es un joven y bravío guerrero [Tacuabé], reconocido por su destreza para domar caballos salvajes; el cuarto [Guyunusa], una mujer, es la compañera del joven guerrero (Paul Rivet, en Azpiroz, 2017).

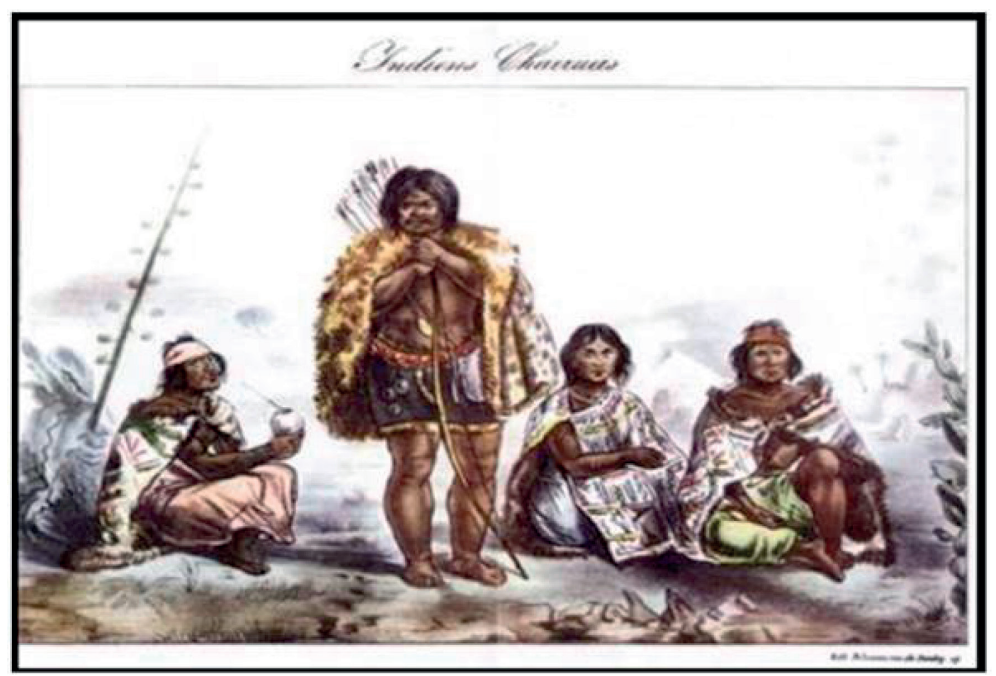

Figura 1. Arthur Onslow (1833), Indiens Charruas, litografía. Fuente: Azpiroz, 2017.

Otra conocida imagen de estos mismos charrúas es la xilografía de Bernard (1833), "Les sauvages charrúas" que acompañó una nota periodística de la época. Aquí, vemos a los "salvajes" vestidos con pieles y harapos, en posición de abatimiento y enfermedad.

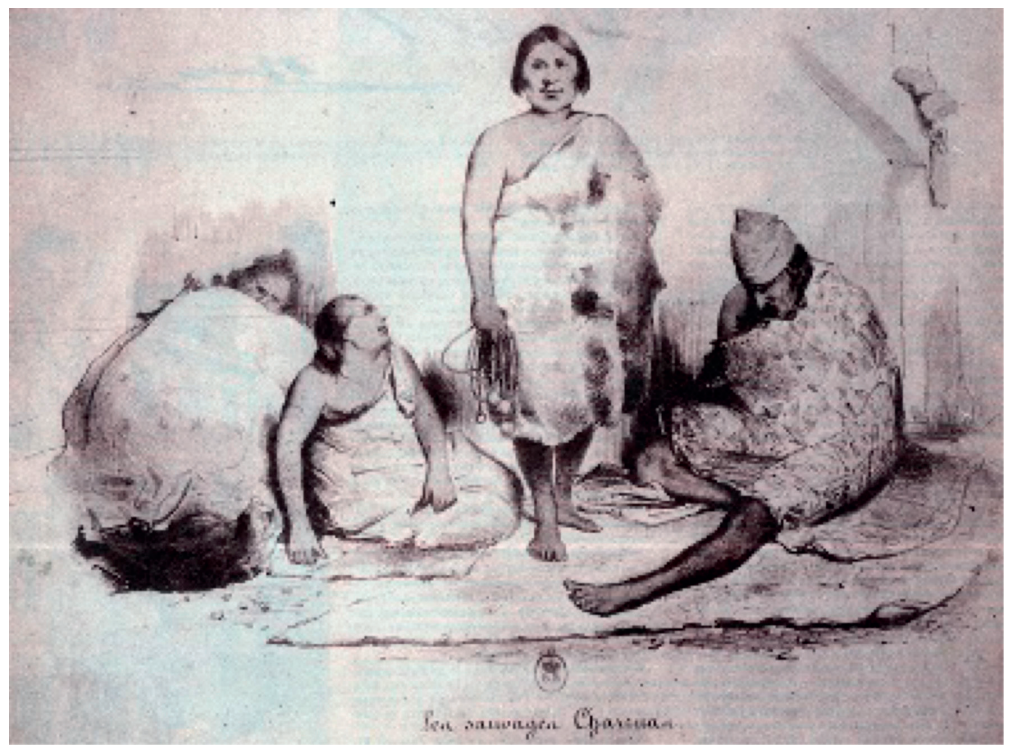

Figura 2. Bernard (1833), Les sauvages charrúas, xilografía. Disponible en Internet: https://montevideoantiguo.net/index.php/blog/heine-y-los-charruas.html Consultada el: 24 de junio de 2020 . 
Combinadas, estas dos piezas se hacen eco de la representación que Figueira elaboraba de los charrúas en "Los primitivos...": un pueblo belicoso, exótico y enfermo, próximo a su extinción.

\section{Francisco Bauzá y el evolucionismo unilineal}

Al mismo tiempo que Spencer influía sobre muchos pensadores del Plata, otras ideas evolucionistas permeaban en la intelectualidad de la región. Una de ellas tenía que ver con la unidad psíquica de la humanidad: la idea de que la mente humana, independientemente de si se trata de pueblos primitivos o civilizados, funcionaba invariablemente a partir de los mismos principios. Sobre esta noción se sostenía el evolucionismo unilineal de autores como E. B. Tylor y L. H. Morgan.

En el caso de Tylor, la unidad psíquica del hombre se refleja en algunos detalles sutiles de su obra -no por su sutileza poco provocadores. Por ejemplo, el título de su libro Primitive culture de 1871, llevaba implícita la idea de que, así como hay cultura en el mundo civilizado también hay cultura en las sociedades primitivas. La propuesta de que la mente humana funciona a partir de los mismos mecanismos, independientemente de la cultura, contradecía la diferencia tajante entre salvajes y civilizados propuesta por Spencer. La clásica definición de cultura de Tylor también reflejaba esta premisa:

La Cultura o la Civilización, tomada en su amplio sentido etnográfico, es ese complejo conjunto que incluye el conocimiento, las creencias, las artes, la moral, las leyes, las costumbres y cualesquiera otras aptitudes y hábitos adquiridos por el hombre como miembro de la sociedad (Tylor, [1871] 1981: 19, la cursiva es mía).

Al entenderla "en un amplio sentido etnográfico", y asignarla al "hombre como miembro de la sociedad", Tylor asociaba la cultura a cualquier individuo miembro de una sociedad, en cualquier contexto etnográfico. Es decir, así como el londinense de fines del siglo XIX, el miembro de la tribu san o el charrúa estaban enlazados por un principio común: eran poseedores de cultura.

La premisa de la unidad psíquica también inspiró al método comparativo de Tylor. Para este autor, las sociedades simples y complejas eran comparables porque la mente humana se desarrolla sobre los mismos principios. Si la mente funciona de la misma forma en todas las culturas, entonces las sociedades deberían desarrollarse de forma similar -haciéndolas comparables entre sí.

En el otro lado del Atlántico, la misma idea de unidad psíquica cristalizó en el modelo evolutivo de Morgan. Al igual que Tylor y otros evolucionistas del siglo XIX, Morgan entendía la evolución cultural de forma progresiva y unilineal. Así, propuso la existencia de tres grandes estadios sucesivos de civilización aplicables a cualquier sociedad: salvajismo, barbarie y civilización, cada uno definido a partir de rasgos determinados. Su famosa afirmación de que "el hombre empieza su vida al pie de la escala, labrando su ascenso, del salvajismo a la civilización, mediante los lentos acopios de la ciencia experimental" (Morgan, [1877] 1980: 77) sintetiza lo anterior.

Una de las obras que refleja la influencia del evolucionismo unilineal en la región del Plata es Historia de la dominación española en el Uruguay (1895), del historiador uruguayo Francisco Bauzá. Si bien Morgan y Tylor no aparecen 
citados en las referencias bibliográficas de este libro, esta obra toma cierta distancia de la separación tajante entre salvajes y civilizados de Spencer. Es cierto que encontramos en Bauzá un discurso que resalta la distancia evolutiva entre los pueblos indígenas y los conquistadores españoles y portugueses. Sin embargo, Historia de la dominación... constituye, como señala Azpiroz (2017), el primer intento de describir positivamente a los charrúas. Por ejemplo, en el primero de los tomos que conforman esta obra, Bauzá presenta a los charrúas como un pueblo caracterizado por una combinación de "bondad natural" y "valentía heroica", reflejada en sus cualidades morales:

La lucha por la existencia emprendida todos los días contra la naturaleza y sus semejantes, y frecuentemente contra ambos a la vez, les había dado la conciencia de su valor, sin ninguno de los agregados con que la vanidad suele afear ese don tan precioso en el hombre. No eran crueles con los vencidos, ni brutales con la mujer, ni autoritarios con los niños (Bauzá, [1895] 1965: 207).

A lo largo de las páginas de Historia de la dominación, Bauzá enumera una serie de rasgos que presentan con un tono positivo a los charrúas frente al lector. Por ejemplo, contradice a Figueira asignando cierto carácter complejo a su sociedad, destacando su división del trabajo en la pesca y en la caza y señalando que "tenían idea de la divinidad y presentían una vida futura [...] [y que] no puede inferirse que profesasen una religión positiva, pero tampoco puede afirmarse que no tuvieran ninguna" (Bauzá, [1895] 1965: 231, la cursiva es mía). Por otra parte, presenta a los charrúas como "astutos y avisados, pero no rencorosos" (Bauzá, [1895] 1965: 231) y objeta el mito extendido de la antropofagia charrúa. Por último, basado en crónicas de Schmidel, del Barco Centenera y Díaz de Guzmán asigna un mayor nivel de organización social y política a los charrúas que Figueira, señalando que al momento de la conquista "las tribus uruguayas formaban una confederación [...] para mantener guerras, alianzas o tratos comerciales con todas las tribus del tránsito" (Bauzá, [1895] 1965: 205).

A pesar de estos rasgos positivos, Bauzá no deja de reconocer el carácter incivilizado de los charrúas presentándolos como una "comarca de indios salvajes" (Bauzá, [1895] 1965: 69), cuyas relaciones estaban dominadas por "una rusticidad primaria" (Bauzá, [1895] 1965: 206), con una lengua pobre y calificando su cultura material como una "transformación grosera de la materia" (Bauzá, [1895] 1965: 224). El siguiente pasaje es ilustrativo de lo anterior:

Por las líneas generales que se dejan trazadas, puede juzgarse el cuadro que presentaba la civilización uruguaya a la hora del descubrimiento. Todo en ella era primitivo. Hombres, instituciones, gustos y costumbres. Hay algo tétrico en la melancolía imperante entre esas masas de bárbaros sin cánticos ni juegos, ensimismados en un silencio que sólo se rompe brevemente para emitir sus opiniones en las asambleas deliberantes, o para darse la palabra de orden frente al enemigo (Bauzá, [1895] 1965: 229).

Por oposición, es tajante el contraste entre esta descripción y la que hace Bauzá de los españoles y portugueses al comienzo de su libro:

Dos naciones, por distintos conceptos ilustres, franquearon al pueblo uruguayo el camino de su transformación, al disputarse la propiedad del territorio donde fundaban establecimientos destinados a perpetuar el progreso, de que ambas eran depositarias y propagadoras [...]. España y Portugal, por la liberalidad de sus instituciones, la ciencia de sus escuelas, el valor de sus navegantes y guerreros, y la aptitud emprendedora de su comercio, ocupaban entonces el 
primer puesto en el concierto de las nacionalidades. Exuberantes de vida, se habían derramado por el mundo conocido [...] y de aquella rivalidad nació la época moderna, cuyos beneficios gozamos merced a sus portentosos esfuerzos (Bauzá, [1895] 1965: 69-70).

Los pasajes anteriores muestran cómo, a pesar de que Historia de la dominación... constituye un giro en la forma de describir a los charrúas aún mantiene un supuesto evolucionista que los ubica en un estadio anterior al de sus conquistadores. Este estadio, según Bauzá, es el neolítico, caracterizado en los charrúas por el dominio de la técnica de la piedra pulida en armas, utensilios de trabajo, etc. Estos artefactos son evidencia para el autor de que los charrúas "habían entrado ya al segundo período de la Edad de piedra, en la cual los rudimentos de una industria menos grosera, comenzó a abrir horizontes más vastos al espíritu humano" (Bauzá [1895] 1965: 248). Verdesio (2005) ha observado que Bauzá utiliza esta periodización de la historia del hombre para ubicar a los charrúas a larga distancia del ideal civilizatorio occidental, en un continuum universal que los comprende a ellos y a todos los pueblos. Los charrúas "no lucen muy bien en el marco de ese modelo, porque se los coloca en un estadio de evolución previo al de la civilización occidental actual" (Verdesio, 2005: 6). Una vez más, vemos manifiesta aquí la influencia del evolucionismo unilineal.

Pero el atraso civilizatorio que Bauzá observa en los charrúas no agota su interés en comprenderlos. De hecho -y creo que este es un aspecto muy importante de su obra-, el autor se desmarca de quienes lo precedieron -de Figueira y, por supuesto, de los cronistas europeos- y procura hacer justicia con los charrúas analizándolos en su contexto, como "una estatua desunida en el taller de un artista, para ser materia de estudio y no incentivo a la obcenidad" (Bauzá, [1895] 1965: 205). Bauzá es severo con quienes recurren a "recargar las sombras del cuadro presentado por las naciones bárbaras de América, ya para enorgullecerse con la comparación, ya para repugnar toda solidaridad entre aquellos gentíos y las sociedades presentes" (Bauzá, [1895] 1965: 247), pues nada es más ajeno a la imparcialidad que un estudio de este tipo requiere. Por lo tanto, "los indígenas uruguayos, al igual que toda sociedad humana, tienen derecho a ser juzgados dentro del criterio moral impuesto a los hombres por su específica solidaridad a través del tiempo" (Bauzá, [1895] 1965: 247).

Para Bauzá, la desaparición de los charrúas fue un efecto natural e inevitable del choque entre una civilización primitiva, que existía en un pasado neolítico, con otra superior, conquistadora, que encarnaba el ideal de progreso y representaba la cúspide del pensamiento, la industria, y los valores deseables del pináculo civilizatorio. Pero, como evidencian los pasajes citados, estos rasgos conviven con la visión humanista de Bauzá frente a la alteridad indígena, manifiesta en el tono tolerante y humanitario presente en las descripciones de los charrúas del autor.

\section{Un retorno a Spencer en Orestes Araújo}

Ya entrado el siglo XX, Uruguay atravesaba un histórico proceso de centralización y modernización del Estado, impulsado durante las dos presidencias de José Batlle y Ordóñez (1903-1907 y 1911-1915). El fracaso de la Revolución de 1904, liderada desde el campo por el caudillo Aparicio Saravia frente a las fuerzas de seguridad estatales, supuso la consolidación de un gobierno central de corte reformista y modernizador. 
En este contexto, Orestes Araújo escribió Historia de los charrúas y demás tribus indígenas del Uruguay (1911). Araújo, quien al igual que Figueira fue autor de libros sobre pedagogía y reforma educativa, impulsó el centralismo de la escuela pública, en oposición a su descentralización en el campo (Tani y Rossal, 2019). Este estadocentrismo se plasma en Historia de los charrúas...donde Araújo desarrolla una visión superadora de lo indígena por la modernidad, representada en el momento de contacto por los conquistadores españoles y portugueses y cristalizada en su tiempo por un Estado moderno y centralizado. Así, el autor se propone ahondar en el conocimiento sobre los charrúas, ajustándose a "los preceptos de la ciencia etnográfica", y revisar descripciones previas de los charrúas por parte de historiadores que "falsearon la verdad" producto de "falta de suficiente observación", "espíritu dogmático" e "imaginación extraviada", y describieron a los charrúas como "un pueblo dotado de una civilización ligeramente inferior a la nación conquistadora", y no como lo que en realidad eran: "hordas bárbaras" (Araújo, 1911: 9-10).

Araújo no se reconoce explícitamente influido por las ideas de Spencer, pero no es difícil advertir huellas del pensamiento spencieriano en su obra, tal vez producto de sus lecturas de Figueira. De hecho, existen múltiples coincidencias entre estos dos autores. Frente una arqueología nacional aún incipiente, Araújo vuelve a revisar en su texto a cronistas de los siglos de conquista para llegar a conclusiones similares a las de Figueira. Las referencias a Los primitivos... afloran en Historia de los charrúas.... Esto es llamativo. Casi dos décadas separan ambos textos y, como fue desarrollado, entre medio de ambas obras sucedió un cambio de representación de lo charrúa en el campo intelectual y artístico uruguayo (Azpiroz, 2017). Parecería que Araújo ignorase deliberadamente este giro, reivindicando una visión conservadora de lo charrúa y acentuando la diferencia entre civilización y barbarie.

$\mathrm{Al}$ igual que Figueira, Araújo presenta un cuadro general de las "cualidades morales" de los charrúas, caracterizándolos como "guerreros", "turbulentos", "vengativos", "crueles" y "falsos". Así,

aferrados a su libertad salvaje, jamás quisieron someterse a nadie ni ajustar sus acciones al marco de una vida sosegada, metódica y regular, a pesar de los continuos trabajos que para conseguirlo llevó a cabo en diferentes épocas el cabildo de Montevideo (Araújo, 1911: 56).

Por otra parte, señala que:

Tan adustos eran estos indígenas, que las madres no acariciaban a sus hijos; tan apáticos que nada les conmovía [...] Apenas reían, hablaban en voz baja o no hablaban, faltando a su voz ese timbre suave o fuerte, pero sonoro y claro, que distingue al hombre civilizado del salvaje. Poco perseverantes, sólo en el espionaje y en la caza demostraban tener mucha paciencia (Araújo, 1911: 56-57).

En cuanto a las "condiciones intelectuales" de los charrúas, Araújo les reconoce un sentido de la vista desarrollado aunque se apura a señalar:

esto no es un síntoma de mayor desenvolvimiento intelectual, sino el resultado de una ejercitación obligada, pero parcial y por consiguiente incompleta" (Araújo, 1911: 60) [...] La inferioridad intelectual de los charrúas está plenamente evidenciada por el grado ínfimo de su cultura general (Araújo, 1911: 59) [ ... y] la idea de civilización estaba tan alejada de su inteligencia 
que les era imposible comprenderla ni asimilársela. Nada excitó nunca sus adormecidas facultades intelectuales (Araújo, 1911: 61).

La descripción es de un salvajismo animal:

Procedían por instinto, o impulsados por la necesidad, siendo incapaces, por falta de suficiente inteligencia de mejorar el medio en que vivían, a pesar de tener en los indios misioneros ejemplos que no les hubiera sido difícil seguir (Araújo, 1911: 60).

Nuevamente, The principles of sociology sirve de punto de referencia para trazar correspondencias entre el pensamiento de Spencer y el de Araújo. Allí, el autor inglés sostiene que el rasgo principal de la emocionalidad del hombre primitivo es la impulsividad (Spencer, en Stocking, 1991), y Araújo apunta a lo mismo al destacar el carácter poco perseverante del charrúa. Asimismo, el salvaje para Spencer es vengativo e intolerante a cualquier límite, dos cualidades señaladas por Araújo en referencia a los charrúas. De la misma forma, sobre el intelecto del salvaje Spencer sostiene que no tienen ideas generales, mucho menos de una relación causal, algo que condice con la descripción del pensamiento instintivo del charrúa al que se refiere Araújo. Finalmente, Spencer señala que el salvaje tiene un sentido y percepción muy agudos del entorno, así como una capacidad de observación detallistas, que se traducen en habilidades en las actividades que requieren actuar por instinto. Sin embargo, son incapaces de esbozar pensamientos racionales y deliberados (Spencer, citado en Stocking, 1991). Las consideraciones de Araujo sobre el sentido de la vista de los charrúas, y la contraposición con su "adormecimiento" intelectual, son llamativamente similares a las conclusiones de Spencer.

Por último, quisiera reflexionar sobre el uso de las fuentes en Araújo. Al hablar de la organización social y política de los charrúas, este autor señala que no tenían organización civil y política. Polemizando con Bauzá, declara que "fantasean los que sostienen que las tribus asentadas en el territorio uruguayo formaban una confederación capaz de mantener guerras, alianzas o tratos con otras tribus de tránsito" (Aráujo, 1911: 68). Si bien es cierto que la idea de una confederación charrúa no emerge de la lectura integral de fuentes etnohistóricas coloniales y, por lo tanto, no es prudente reconocer su existencia, ${ }^{7}$ recordemos que Bauzá, y también los cronistas Schmidel, del Barco Centenera y Díaz de Guzmán -citados por Bauzá y por el propio Araújo-, así lo sugerían. De la misma forma, Araújo sostiene que los charrúas "no adoraban ninguna divinidad, ni tenían religión" (Araújo, 1911: 102), y que "el movimiento de los astros no despertaba en ellos ninguna idea, ni aún supersticiosa" (Araújo, 1911: 59). Por su parte, Bauzá prefería mostrarse algo más cauto al respecto, poco convencido de que los cronistas aportaran evidencia tanto sobre la existencia de una religión charrúa como de la ausencia de ella.

Lo anterior llama la atención, al sugerir un uso caprichoso y poco riguroso de las fuentes por parte de Araújo. Al momento de escribir su libro, no existía un corpus de evidencia arqueológica disponible para integrarla a una discusión argumental, por lo que las crónicas etnohistóricas constituían fuentes legitimadas. Sin embargo, aun así, sorprende que Araújo ni siquiera mencione los contrapuntos entre su lectura de las crónicas y la que hace Bauzá. ¿Por qué no aparece en Historia de los charrúas... la cautela de Bauzá en cuanto a la negación de una religión charrúa? ¿Qué es lo que lleva a Araújo a ignorar deliberadamente la observación hecha por los mismos cronistas, a quienes cita como fuentes, sobre la existencia de una confederación indígena que incluía
7. Importa señalar que Schmidel ([1567] 1986o, por ejemplo, señala la existencia de alianzas entre indígenas de distintos grupos étnicos para enfrentar un enemigo comú1n. De esto no surge directamente la idea de una confederación como estructura o relación entre las etnias que poblaban el territorio. Sin embargo, me limito aquí simplemente a la lectura realizada por los autores analizados sobre estas fuentes. 
8. Los autores refieren a un texto en el que Araújo señala un carácter centralista en el proyecto de reforma educativa de José Pedro Varela, quien aunque no estaba a favor de la centralización debió emprender acciones centralistas obligado por la legislación vigente en tiempos de la dictadura de Latorre, y no por motivos ideológicos como da a entender Araújo. "Araújo cae en un sofisma al rebatir el Proyecto vareliano con la práctica vareliana, que se encontraba enmarcada inevitablemente, bajo una legislación centralista. No rebate argumentos con argumentos, y no ofrece la prueba de la retractación de Varela (Tani y Rossal, 2019: 31). a los charrúas al momento de la conquista? Da la impresión de que Araújo utilizó discrecionalmente sus fuentes para sostener un argumento ideológico orientado a subrayar el carácter "salvaje" e "inferior" de los charrúas, más que para -como se propone al principio de su obra- describirlos "apoyándose en los preceptos de la ciencia etnográfica". Esta manipulación argumental por parte de Araújo para sostener una posición ideológica ha sido observada previamente por Tani y Rossal (2019), ${ }^{8}$ en referencia a la reforma educativa de José Pedro Varela.

Volviendo a las influencias teóricas, así como no es posible determinar si Bauzá leyó a Tylor y Morgan, es difícil determinar si Araújo leyó o no a Spencer, ya que no lo cita. Pero hay en Araújo, indudablemente, una lectura spenceriana de los charrúas, posiblemente influido por el trabajo de Figueira. La idea de la inferioridad charrúa presente en la obra de Araújo es un eco de los mecanismos de la evolución social de Spencer descritos anteriormente. Más específicamente, como fue señalado, existen paralelismos entre las descripciones "intelectuales" y "morales" de los charrúas, señaladas por Araújo, y las cualidades atribuidas a los pueblos salvajes por Spencer.

\section{Reflexiones finales}

He intentado analizar algunos textos fundamentales en la construcción discursiva sobre los charrúas en el tránsito del siglo XIX al XX en Uruguay. Los autores de estas obras son miembros de una élite intelectual que comienza a interesarse por historiar a los charrúas algunas décadas luego de su exterminio a manos del Estado Oriental. Resumiendo, podría decirse que la influencia de Spencer sobre Figueira es clara y explícita. Figueira alimenta la idea de inferioridad del pueblo charrúa, a partir de una concepción de salvajismo durante buena parte del siglo XIX. Vemos aquí a un charrúa situado en oposición al proyecto de construcción del Estado Oriental, al cual "fue menester" exterminar para alcanzar la civilización.

Algo similar, aunque no idéntico, sucede con Bauzá. Este autor también parte de un paradigma evolucionista, más próximo a Tylor o Morgan que a Spencer, que sitúa a los charrúas en un estadio inferior al occidente civilizado, concretamente en el neolítico. Pero lo que distingue a la obra de este autor es una voluntad de representar a la alteridad charrúa como parte de un continuum evolutivo que, en el fondo, los une al nosotros con el que el autor se representa. Esta visión, ciertamente tyloriana o morganiana, representa un quiebre con la forma de concebir la otredad en Figueira y es contemporánea a los intentos de reimaginar lo charrúa en la literatura y las artes plásticas de la época (Azpiroz, 2017).

En base a lo anterior, quizás cabe señalar el texto de Araújo como anacrónico. La reminiscencia del pensamiento de Figueira y la ignorancia deliberada de las consideraciones de los charrúas como un pueblo bueno, valiente y heroico que encontramos en Historia de la dominación... de Bauzá, sorprenden en un texto publicado dieciséis años después de este último. Araújo escribe en pleno auge del batllismo, con un Estado modernizado, industrialmente próspero y con un Uruguay abierto hacia la inmigración europea. Tal vez sea este contexto el que lo impulse a acentuar, en un giro conservador, la distancia entre la moderna sociedad uruguaya y sus primitivos antepasados. 
Cualquier abordaje a obras clásicas que pretenda hacer justicia con sus autores debe entenderlas como productos históricos de su tiempo. Ello implica hacerlas dialogar con el contexto del que emergen y leerlas a la luz de los paradigmas dominantes en su época. Sin embargo, aunque más de un siglo nos distancia de los textos analizados aquí, es llamativa la extemporánea vigencia que mantienen algunos de sus preceptos en discursos contemporáneos sobre la identidad uruguaya. Para muchas personas, y a pesar de la existencia de distintos colectivos que actualmente reclaman su reconocimiento como charrúas, Uruguay siempre fue, y continúa siendo, un país sin indios.

Esta narrativa nacional, que relega a los charrúas a "un papel meramente decorativo y distante, a un elemento casi exótico en la historia del país" (Verdesio, 2014: 88), tiene un fuerte arraigo en los discursos de importantes figuras públicas del Uruguay contemporáneo. Por ejemplo, los ex presidentes José Mujica y Julio María Sanguinetti han negado repetidamente el papel de los charrúas en la constitución de la identidad nacional uruguaya, así como las luchas por el reconocimiento de colectivos charrúas, incluso mofándose de ellas. Sin ir demasiado lejos, el 9 de junio de 2020 Sanguinetti subió un video a su cuenta de Facebook ${ }^{9}$ en el que reivindica la figura de Fructuoso Rivera, principal responsable del genocidio charrúa de Salsipuedes, y demoniza a los charrúas a partir de la oposición spenceriana entre salvaje y civilizado. Allí, el ex Presidente representa a la etnia charrúa como un pueblo belicoso y salvaje que "robaba mujeres y niños", "asaltaba estancias", "impedía el asentamiento en los campos", "impedía el trabajo" y que, en general, constituía una amenaza a "la sociedad hispano-criolla, digamos, la nuestra, la del Padre Larrañaga, la de Rivera, la de Oribe, la de Artigas". Apelando a esquemas propios del evolucionismo social y a una pretensión objetiva de la historia, Sanguinetti encarna aquí el sentir colectivo de buena parte de la sociedad uruguaya hacia la etnicidad charrúa. De hecho, esto mismo vale incluso para referentes de la antropología uruguaya, como los ya fallecidos Daniel Vidart o Renzo Pi Hugarte, quienes se manifestaron reiteradamente a favor de minimizar o negar la contribución charrúa a la identidad nacional, desacreditando los reclamos de estos colectivos con burlas -"charrúamanía", al decir de Pi Hugarte- y enfatizando -correctamente- el legado de la etnicidad guaraní, aunque en detrimento de la contribución charrúa (Verdesio, 2014).

Pero las identidades y las culturas no se construyen de forma fija, como una suma de cualidades observables, y tampoco bajo la pretensión objetivante de la narrativa histórica oficial sobre los pueblos. Al final del día, no es el Estado ni los saberes "expertos" de antropólogos, biólogos o historiadores los que determinan sustantivamente qué es cultura o no, ni cuánto tenemos los uruguayos de charrúas o de guaraníes, o si somos más europeos que indígenas. En los hechos, este tipo de procesos son cambiantes y dinámicos, están sujetos a historicidad, disputas y negociaciones permanentes, y sus protagonistas son las personas. ${ }^{10}$ Como apunta Briones (2007), los procesos de identificación deben entenderse de manera performativa; es decir, a partir de lo que la gente hace y las producciones de sentido sobre lo que es cultural y lo que no lo es, derivadas de ese hacer colectivo.

Entonces, revisar la obra de autores como Figueira, Bauzá o Araújo constituye un doble ejercicio. Por un lado, es un aporte al mapear tradiciones de pensamiento que configuraron la forma de pensar el ethos nacional uruguayo, y las influencias del paradigma teórico evolucionista en la configuración del campo antropológico de este país. Por otro, trata de perseguir el rastro de las huellas
9. Disponible en Internet: https://m.facebook.com/story. php?story_fbid=1015832195742443 $1 \& i d=29039654430$ Consultada el: 24 de junio 2020.

10. El concepto de "configuración cultural" propuesto por Grimson (2011) incorpora este sentido. 
evolucionistas que impregnan muchos de los discursos relativos a la etnicidad charrúa en la actualidad.

\section{Agradecimientos}

El autor quisiera expresar su agradecimiento al Dr. Axel Lazzari, al Dr. Gustavo Verdesio, y a los dos revisores anónimos por sus sugerencias y comentarios que contribuyeron a mejorar significativamente el presente texto. 


\section{Q Bibliografía}

" Araújo, O. (1911). Historia de los Charrúas y demás tribus indígenas del Uruguay. Montevideo, Librería Cervantes.

"Azpiroz, A. (2017). De "salvajes" a heroicos: la construcción de la voz y la imagen del "indio Charrúa" desde 1830 a los inicios del siglo XX. Almanack 16: 1-38.

》 Barrán, J. P. (1968). Latorre y el Estado uruguayo. Enciclopedia uruguaya 22: 21-39.

» Bauzá, F. ([1895] 1965). Colección de clásicos uruguayos: Historia de la dominación española en el Uruguay. Tomo I. Montevideo, Biblioteca Artigas.

»Briones, C. (2007). Teorías performativas de la identidad y performatividad de las teorías. Tabula rasa 6: 55-83.

»Cabrera Pérez, L. e I. Barreto (1997). "Indios, frontera y hacendados en el sur de la Banda Oriental" en Behares, L. y O. Cures (eds.), Sociedad y cultura en el Montevideo colonial: 251-264. Montevideo, Facultad de Humanidades y Ciencias de la Educación.

» Figueira, J. H. (1892). Los primitivos habitantes del Uruguay: Ensayo paleoetnológico. Montevideo, Imprenta artística de Dornaleche y Reyes.

» Grimson, A. (2011). Los límites de la cultura. Buenos Aires, Siglo XXI editores.

"Morgan, L. ([1877] 1980). La sociedad primitiva. Bogotá, Editorial Ayuso.

» Pi Hugarte, R. (1997). Sobre la antropología en el Uruguay. Horizontes antropológicos 7: 36-61.

"Scarone, A. (1937). Uruguayos contemporáneos. Nuevo diccionario de datos biográficos y bibliográficos. Montevideo, Casa A. Barreiro y Ramos.

» Schmidel, U. ([1567] 1986). Relatos de la conquista del Río de la Plata y Paraguay 1534-1554. Madrid: Alianza Editorial. (Prólogo [traducción] y notas de Klaus Wagner).

"Spencer, H. (1860). The social organism. Westminster review 73 (143): 90-121.

》Stocking, G. W. (1991). Victorian anthropology. Nueva York, The free press.

"Tani, R. y M. Rossal (2019). La antropología escolar y el mito euhemerístico. Revista Uruguaya de Antropología y Etnografía, Número Especial: 25-42.

》 Tylor, E. B. ([1871] 1981). Cultura primitiva. Madrid, Editorial Ayuso.

"Verdesio, G. (2005). La mudable suerte del amerindio en el imaginario uruguayo: su lugar en las narrativas de la nación de los siglos XIX y XX y su relación con los saberes expertos. Araucaria. Revista Iberoamericana de Filosofía, Política y Humanidades 7 (14): 161-195.

"Verdesio, G. (2014). Un fantasma recorre el Uruguay: la reemergencia charrúa en un "país sin indios". Cuadernos de literatura 18 (36): 86-107. 